Süleyman Demirel Üniversitesi Fen Edebiyat Fakültesi Fen Dergisi

Atıf için / For Citation: İ. Karataş, C. Gök, D. Erden Gönenmiş, Y. Özcan, "Yağlı Boya Tuvallerde Görülen Kirlenmeler ve Hidrojellerle Yüzey Temizlik Tekniklerinin İncelenmesi”, Süleyman Demirel Üniversitesi Fen Edebiyat Fakültesi Fen Dergisi, 16(1), 225-236, 2021

\title{
Yağlı Boya Tuvallerde Görülen Kirlenmelerde Hidrojellerle Yüzey Temizliği
}

\author{
İbrahim KARATAŞ ${ }^{1}$, Cem GÖK$^{2 *}$, Dicle ERDEN GÖNENMIŞ ${ }^{3}$, Yusuf ÖZCAN ${ }^{3}$

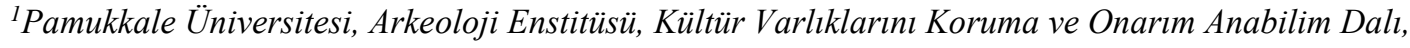 \\ 20070, Denizli, Türkiye \\ ${ }^{2}$ Pamukkale Üniversitesi, Teknoloji Fakültesi, Metalurji ve Malzeme Mühendisliği Bölümü, 20070, \\ Denizli, Türkiye \\ ${ }^{3}$ Pamukkale Üniversitesi, Teknoloji Fakültesi, Biyomedikal Mühendisliği Bölümü, 20070, Denizli, Türkiye \\ *yazışllan yazar e-posta: cemgok@pau.edu.tr
}

(Alinış / Received: 26.03.2021, Kabul / Accepted: 06.05.2021, Yayımlanma / Published: 27.05.2021)

Özet: İşlenen konulara göre yağlı boya tuval resimleri, dönemin sanatı, üslubu, sosyal yaşamı, inancı ve tarihi hakkında bilgi veren taşınabilir en önemli kültür varlıklarından biridir. Bu çalışmada çeşitli nedenlerden dolayı yağlı boya tuvallerde görülen kirlenmelerin biyopolimerik yapıda hidrojeller kullanılarak temizlenmesi amaçlanmıştır. Hidrojeller toksik madde içermemesi ve bunun yanında hızlı ve kolay bir teknikle hazırlanması yönünden birçok avantaja sahiptir. Hazırlanan hidrojeller ile tarihi eser niteliği taşıyan tuval resimlerindeki kirlenmeler yapıya zarar vermeden temizlenmiştir. Kolay ve bol bulunan aljinat ve doğal sakız biyopolimerleri ile hidrojel yapısında temizleme malzemesi hazırlanmıştır. Temizleme işlemlerinin test edilmesi için kimyasal yöntemler ile yaşlandırışmış tuvaller toz, kül ve is ile kirletilmiştir. Kullanılan hidrojel malzemeler kirletilen ve yaşlandırılan tuvallere uygulanması neticesinde sonuçlar farklı mikroskobik ve spektroskopik yöntemlerle incelenmiştir. Optik mikroskop, Taramalı Elektron Mikroskobu (SEM) ve Fourier Dönüşümlü Kızı̈ötesi Spektrofotometresi (FT-IR) analiz yöntemleri kullanılarak malzemelerin karakterizasyonu gerçekleştirilmiştir.

Anahtar kelimeler: Hidrojeller, Temizlik teknikleri, Aljinat, Yüzey kirleri, Yağlı boya tuval

\section{Surface Cleaning of Contaminated Oil Painting Canvas with Hydrogels}

Abstract: According to the subjects covered, oil painting canvas are one of the most important movable cultural heritage that provide information about the art, style, social life, belief and history of the period. In this study, it was aimed to clean the dirt due to various reasons on oil canvas by using biopolymeric hydrogels. Hydrogels have many advantages in that they don't contain toxic substances and can be prepared with a fast and easy technique. The dirt on the canvas paintings that are historical artifacts were cleaned without damaging the building with the hydrogels prepared. Hydrogel structure was prepared as a cleaning material with plentiful and readily available alginates and natural gums biopolymers. The canvases aged by chemical methods were contaminated with dust, ash and soot to test the cleaning processes. As a result of the application of the hydrogel materials used on polluted and aged canvases, the results were 
analyzed with different microscopic and spectroscopic methods. The characterization of the materials was carried out using analysis methods as optical microscope, Scanning Electron Microscope (SEM) and Fourier Transform Infrared Spectrophotometer (FT-IR).

Key words: Hydrogels, Cleaning techniques, Alginate, Surface dirt, Oil paint canvas 


\section{Giriş}

Konservasyon ve restorasyonda yağlı boya tuvallere, aktif ve pasif yöntemlerle koruma ve onarım yapılmaktadır. Aktif konservasyonda yağlı boya tuvallere direkt müdahaleler gerekse de pasif konservasyonda eserlere doğrudan müdahaleler gerekmemektedir. Yağlı boya tuval resimlerinin konservasyon ve restorasyonunda uygulanan bu yöntem ve tekniklerin sirasi;
a) Belgeleme
b) Teşhis
c) Uygulama'dir.

Uygulama basamakları; sağlamlaştırma, yüzey temizliği, rötuş ve vernik sürme gibi işlem basamaklarından oluşmaktadır [1]. Şekil 1'de Konservasyon ve restorasyonda yağlı boya tuvallere uygulanan yöntemlerin işlem sıralaması gösterilmiştir.

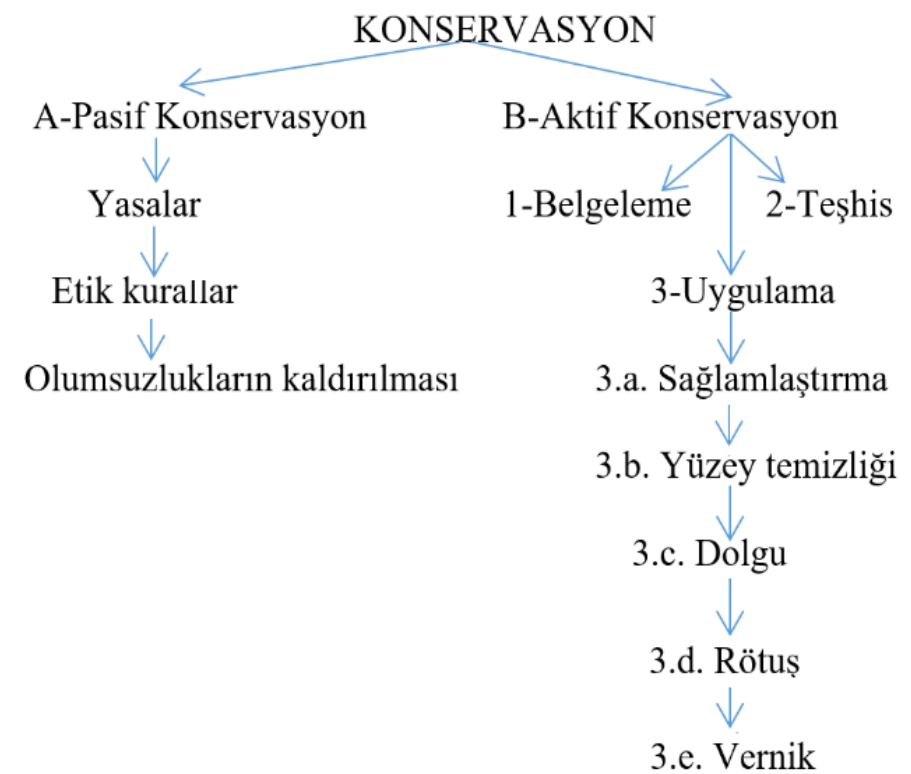

Şekil 1. Konservasyon ve restorasyonda yağlı boya tuvallere uygulanan yöntemlerin işlem sirasi.

Yüzey temizliğinde yağlı boya tuvallerin yüzeyinde zamanla oluşan kir, toz, yangınlar neticesinde oluşabilecek is, kül, yağlı boyalarda kullanılan bağlayıcı ve inceltici maddelerden gelen yağ, çok uzun bir süreç sonunda yüzeye ulaşarak kir oluşturabilir. $\mathrm{Bu}$ yağ kirleri ile beraber, bozulmaya uğramış vernikli veya rötuşlu alanlar temizlenir. Yağlı boya tuval resimleri estetik kaygı taşıyan üst üste oluşturulmuş farklı katmanlardan meydana gelmektedir. Tuval resimleri bazen kısa zamanda, bazen ise uzun bir çalışma sonucunda ortaya çıkabilir. Bu aşamaları ilk önce yapılan işlemden, en son yapılan işlem basamaklarına doğru sıralamamız gerekirse; şase (şasi), taşıyıcı yüzey (canvas), astarlı yüzey, boya katmanları ve vernik (verni)'ten oluşmaktadır [2]. Yağlı boya tuvallerin yüzeyine uygulanan vernik uzun zaman sonucunda geçirdiği fiziksel ve kimyasal değişimlerden dolayı, farklı şekillerde bozulma ve yıpranmalar meydana getirmektedir. Tuval yüzeyine uygulanan bu vernikler uzun yıllar sonucunda görünüşündeki saydamlığını yitirerek, yüzeydeki boyalardan başlayıp, tüm katmanlardaki boyalarla birleşerek, önlenemez tahribatlara sebep olabilmektedir [3]. Eski zamanlarda yapılmış yağlı boya tuvallerde, kömür tozu ve sigara dumanı birlikte bütünleşerek ve tuval yüzeyindeki yağlı yerler ile birleşerek, partiküllerin katranlaşmasına ve kuvvetli bir tabaka oluşmasına sebep teşkil etmiştir [4]. Yağlı boya 
tuval resmi yapmada kullanılan boyaların içlerinde bağlayıcı olarak bulunan yağ miktarı ve ressamlar tarafından yapılış yöntemlerine göre siyahlaşma durumu oluşabilmektedir [5]. Müze arşivlerinden ulaşılan bilgilere göre, yağlı boya tuvallerin yüzey kirleri ve vernik tabakaları yaklaşık olarak elli yılda bir temizlenmektedir [6]. Yağlı boya tuvallerin boya katmanı ya da resimleri korumak için yüzeyi bir film tabakası gibi örten, vernikli yüzey katmanı üzerinde uzun bir süreçte oluşan "tortular", yüzey kirleri olarak adlandırılırlar. Yüzeyde oluşan kirlerin ana kaynakları önceki restorasyonlar, atmosfer ve tuvallerde meydana gelen biyolojik olaylardır. Yağlı boya tuvaller yapılırken kullanılan, tuvalleri meydana getiren ana malzemelerden kaynaklı bozulmalar olabilir. Atmosfer olayları yağlı boya tuvallerin çevresine, resim katmanlarının üzerinde oluşan kirli maddeleri katı, sıvı ve gaz şeklinde taşırlar. Daha evvelki zamanlarda yapılan restorasyon ve konservasyonlardan resim katmanı yüzeyinde parmak izleri, ip, çözücü ile resim çerçevesi tamir ve bakımından kalan kalıntılar bulunabilir. Vernik kullanılmayan tabakalar üzerinde, mat renkler ve boya tabakalarından kaynaklı "kusma" adı verilen yağ asitleri sonucu bozulmuş malzemeler görülebilir. Bazı kişilere ait tuval resimleri ve kamuya ait binalarda bulunan eserlerde, gazlı içeceklerden sıçrayan sıvılar, kurumuş sprey kalıntıları, boya partikülleri, süsleme ve kutlama kaynaklı kirlenmeler, hata sonucu sıçramış katı ve sıvı maddeler yağlı boya resim tabakaları üzerinde bulunabilir. Parlak görünümlü vernik katmanları yüzeyinde zamanla oluşan kir ve tozlar 1şığın yansıması sonucu gri bir tülmüş gibi görülebilirler. Tuvallerin yüzeyindeki vernik katmanı akışkan şekilde ise kir ve toz partikülleri sarı renkten kahverengiye doğru çeşitli biçimlerde görüntü verebilirler [6]. Dışardan müzelerin içerisine tozlar ile ulaşan farklı böcek çeşitleri, organik malzemeden yapılmış tuvallerden veya tuvallerin tabaka yüzeyleri üzerinde zamanla biriken boyalarda bağlayıcı olarak kullanılan yağlardan beslenebilirler [7]. Yağlı boya tuvallere uygulanan yüzey temizliği uygulamaları yirminci yüzyıla kadar gerekli hassaslık gösterilmeden yapılmıştır.

Bu çalışmada yağlı boya tuvallerin kirlenen yüzeylerinin temizlenmesine farklı bir bakış açısı getirecek yeni bir yöntemle, yapıya zarar vermeden kirlenmenin temizlenmesi için bir metot önerilmektedir. Bu amaçla aljinat ve doğal sakız kullanılarak elde edilen hidrojellerle temizlik işlemi gerçekleştirilmiş ve çeşitli karakterizasyon teknikleri ile değerlendirilmiştir.

\section{Materyal ve Metot}

Eski eser niteliği taşımayan tuval asitsiz akrilik astarlıdır. Tuvalin ebatları; $25 \times 35 \mathrm{~cm}$ boyutlarında, şasesi $16 / 25 \mathrm{~mm}$, astar yüzeyi $\% 100$ pamuk $280 \mathrm{gr} / \mathrm{m}^{2}$, gibi özelliklerden oluşmaktadır. Winsor \& Newton markası taşıyan renklendiriciler yağlı boya tuval resmi yapımında kullanılmıştır. Resim yapımında tercih edilecek renklendirici özellikle ışık haslığı değeri olan; (PW6) opak titanyum beyazı, (PBk9) opak fildişi siyahı, (PW5) opak kobalt mavisi, (PY74) opak orta kadmiyum sarısı ve (PR177) şeffaf garans (alizarın kırmızısı) renkler seçilmiştir. Boyaların akışkanlığını artırmak için beziryağı ve kokusuz terebentin tercih edilmiştir. Yağlı boya tuval yapımında boyaların renklerini tonlamak için titanyum beyazı ve fildişi siyahı ana renkler ile beraber kullanılmıştır [8]. Kontrast (zıt) renkler ana renklerin birbirleri ile karıştırılmasından elde edilmiştir. Şekil 2 'de gösterildiği gibi çalışmada bir ' genç kız portresi' yapılmıştır. 


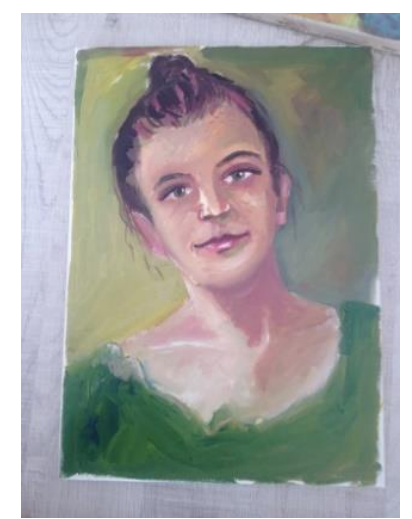

Şekil 2. Tuval yüzeyine yağlı boyalarla yapılan 'genç kız portresi”'

\subsection{Tuval resmi yaşlandırma işlemleri}

Hassas terazide yeni yapılan yağlı boya tuvalden makasla kesilerek 1,75 g tartılmıştır. Yağlı boya tuvali yaşlandırmak için tuval parçaları beher içindeki $130 \mathrm{ml}$ distile su ve $70 \mathrm{ml}$ hidrojen peroksit $\left(\mathrm{H}_{2} \mathrm{O}_{2}\right)$ içerisine bırakılmış olup, 200 rpm'de manyetik karıştırıcıda karıştırılmıştır. Karışım $25{ }^{\circ} \mathrm{C}^{\prime}$ de 72 saat boyunca karışmaya bırakılmıştır. Tuvaller manyetik karıştırıcıdan çıkarıldıktan sonra temizliği distile su ile yapılmıştır. Sonraki aşamada ise etüvde $40{ }^{\circ} \mathrm{C}$ kurutulmuştur [9]. Şekil 3 'te yağlı boya tuval yaşlandırma deneyi, oda sıcaklığında ve etüvde kurutma şekilleri gösterilmiştir.
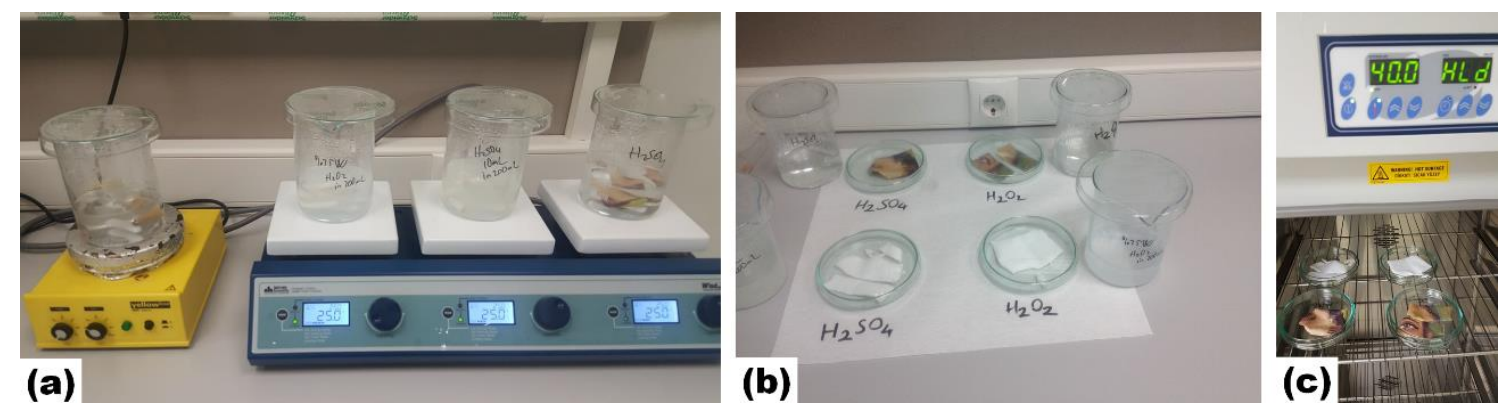

Şekil 3. (a) Yağlı boya tuval yaşlandırma deneyi, (b) oda sıcaklığında ve (c) etüvde kurutma yöntemi.

Boş tuvaller, yağlı boya tuvallerle aynı şekilde eskitilmiştir. Kuruma işlemi oda sıcaklığında yapılmıştır [10]. Şekil 4' te $\mathrm{H}_{2} \mathrm{O}_{2}$ kullanılarak yaşlandırılmış resimli tuval yüzeyleri görülmektedir.
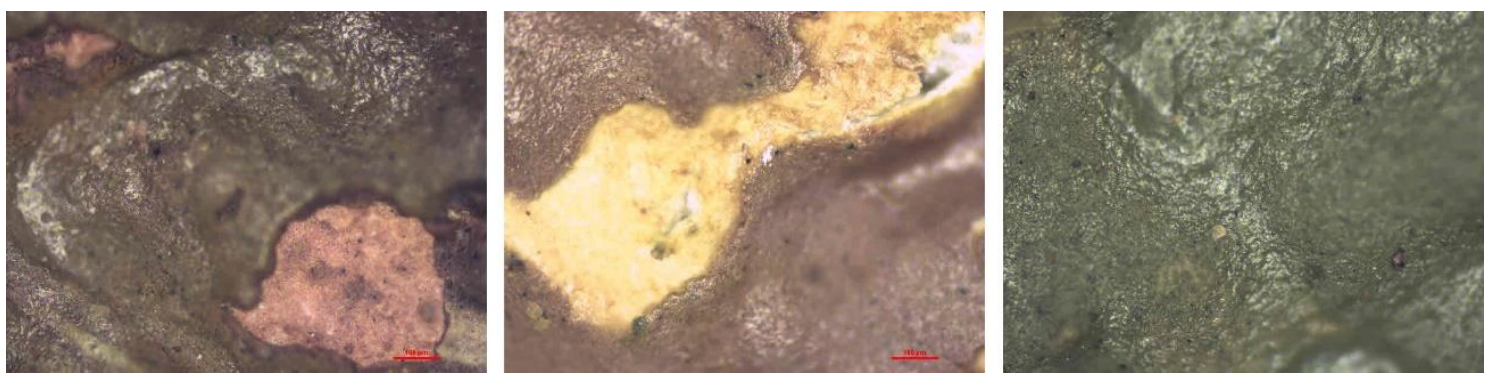

Şekil 4. $\mathrm{H}_{2} \mathrm{O}_{2}$ kullanılarak yaşlandırılmış resimli tuval yüzeyleri

\subsection{Yaşlandırılmış tuval resminin kirletilmesi}

$70 \mathrm{ml}$ hidrojen peroksit $\left(\mathrm{H}_{2} \mathrm{O}_{2}\right)$ ve $130 \mathrm{ml}$ distile su ile yaşlandırma işlemi yapılmış olan $1,75 \mathrm{~g}$ ağırlığındaki tuval, etüv kullanılarak $40{ }^{\circ} \mathrm{C}$ 'de kurutulduktan sonra kül ve toz kullanılarak kirletme işlemi yapılmıştır. $\mathrm{H}_{2} \mathrm{O}_{2}$ kullanılarak yaşlandırılmış toz ve kül ile kirletilmiş resimli tuval yüzeyleri Şekil 5 'te görülmektedir. 

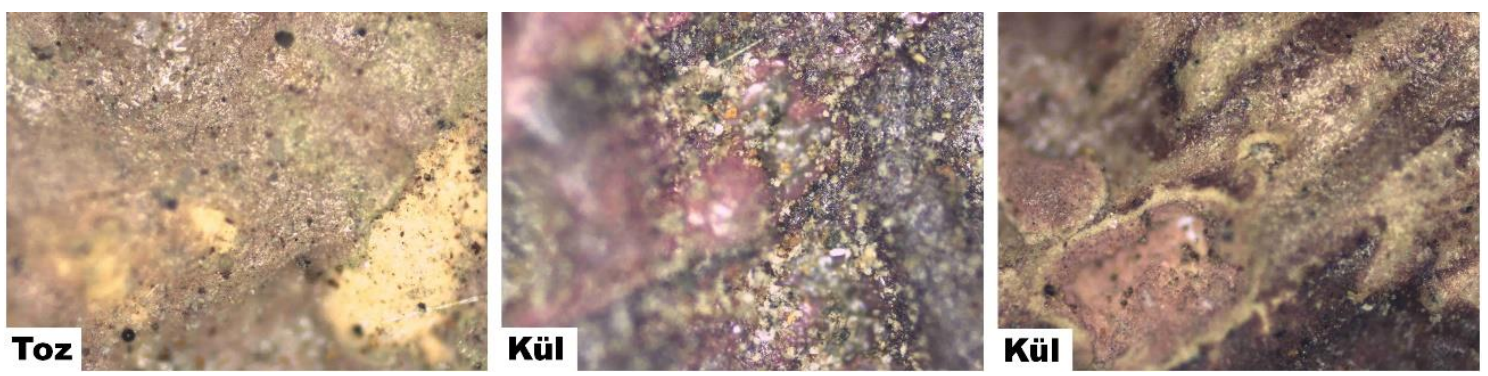

Şekil 5. $\mathrm{H}_{2} \mathrm{O}_{2}$ kullanarak yaşlandırılmış toz ve kül ile kirletilmiş resimli tuval yüzeyleri

Boş tuvaller aynı koşullarda yaşlandırma, kirletme işlemlerine tabi tutulmuş olup 72 saat oda sıcaklığında kurutulma işlemi uygulanmıştır. Şekil 6'te $\mathrm{H}_{2} \mathrm{O}_{2}$ kullanılarak yaşlandırılmış is ve kül ile kirletilmiş boş tuval yüzeyleri görülmektedir.

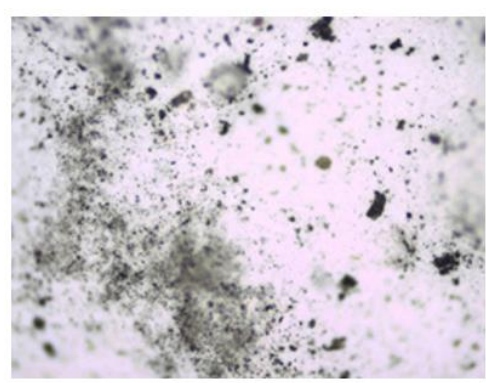

İs

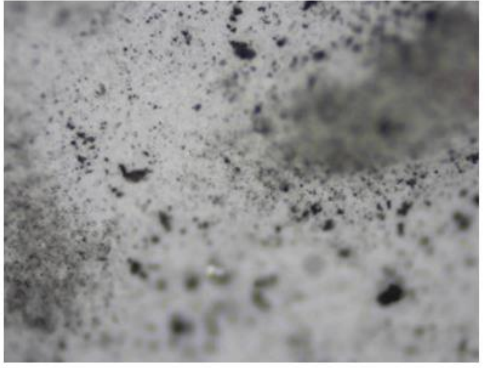

İs

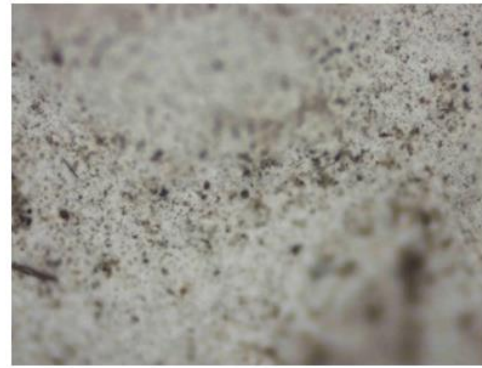

Kül

Şekil 6. $\mathrm{H}_{2} \mathrm{O}_{2}$ kullanılarak yaşlandırılmış is ve kül ile kirletilmiş boş tuval yüzeyleri

\subsection{Hidrojel malzemelerin hazırlanmast}

Yapılan çalışmada, biyopolimerlerin özel bir türü olan hidrojeller kullanılarak yaşlandırma işlemi yapılmış, bozunmaya uğramış ve yüzey kirliliğine maruz kalmış yağlı boya tuvallerin, yüzeylerinin temizlenme işlemleri yapılmıştır. Kullanılan aljinat hidrojelleri, Na-aljinat iyonlarının kalsiyum ile polimerleşmesi sonucu elde edilmiştir. Malzemelerin hazırlanmasında, öncelikle $25 \mathrm{ml}$ saf su, tartılan Na-Aljinat üzerine ilave edilmiş ve el ile $60^{\circ} \mathrm{C}$ 'de, manyetik karıştırıcı üzerinde karıştırılmaya başlanmıştır. El ile karıştırılmasının nedeni, manyetik bar kullanıldığında bar üzerinde oluşan jelin, birikmesinin önüne geçilmesidir. Hidrojel elde etmek için, çözelti $60{ }^{\circ} \mathrm{C}$ 'de tamamen çözdürülerek jel kıvamı elde edilip, $1 \mathrm{M} \mathrm{CaCl}_{2}$ çözeltisi eklenmiştir. Daha sonra bu karışım 300 rpm'de hızdaki manyetik karıştırıcı üzerinde 7,35 g içine $100 \mathrm{ml}$ saf su ilavesi yapılarak karıştırılmıştır. Yapılan çalışmada $\mathrm{CaCl}_{2}$ kullanılmasının en önemli nedeni, elde edilen biyokompozit küreciklerinin istenilen yapıda ve kararlılıkta olmalarının yansıra ucuz ve kolay elde edilmeleridir [9].

Hassas terazide 2,00 g günlük sakızı, doğal sakız kullanılarak sakız çözeltisi hazırlamak için tartılmıştır. Beher içine konulan $95 \mathrm{ml}$ distile su üzerine $5 \mathrm{ml}$ asetik asit eklenen bu karışıma günlük sakız ilave edilerek cam baget yardımıyla bir süre mekanik olarak karıştırıldıktan sonra tekrar $300 \mathrm{rpm}$ karıştırma hızında $50^{\circ} \mathrm{C}$ 'de manyetik karıştırıcıda karıştırılma işlemine tabi tutulmuştur. Safsızlıklardan ayrıştırmak içinde yeterli karışma seviyesine gelen sakızı adi süzgeç kağıdı yardımıyla süzerek birkaç kez saf su ile yıkanmıştır. 1M, $100 \mathrm{ml}$ kalsiyum klorür çözeltisi hazırlamak için beherde bir miktar distile suya hassas terazide ölçülen $11,101 \mathrm{~g} \mathrm{CaCl}_{2}$ ilave edilip karıştırıldıktan sonra balon jojeye aktarılan karışıma joje sınır çizgisine kadar distile su ilavesi yapılmıştır. Aljinat çözeltisi hazırlamak için hassas terazide tartılan $1 \mathrm{~g}$ aljinata $50 \mathrm{ml}$ distile su eklenerek elde edilen karışım 100 rpm'de $40{ }^{\circ} \mathrm{C}$ altında çözünene kadar manyetik 
karıştırıcıda karışma işlemine tabi tutulmuştur. 30 dakika boyunca 500 rpm'de manyetik karıştırıcıda süzme işlemine tabi tutulduktan sonra süzülmüş olan sakızın üzerine aljinat çözeltisi yavaş yavaş ilave edilerek karıştırılmıştır. Karışma işleminden sonra karışım üzerinde oluşan köpükler alınarak karışım petri kaplarında bulunan kalsiyum klorür çözeltisi üzerine dökülmüştür. Tozlanmaya karşı ve nemi korumak için petri kaplarının üzeri örtülmüştür. Şekil 7'de yaşlandırılmış, kirletilmiş resimli ve boş tuvallerin yüzey kirlenmelerini temizlemek için kullanılacak aljinat-sakız karışımı film hazırlama safhaları gösterilmiştir.

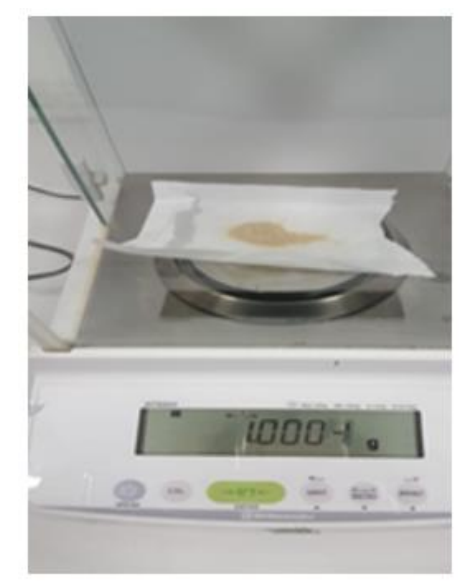

Aljinatın hassas terazide ölçülmesi

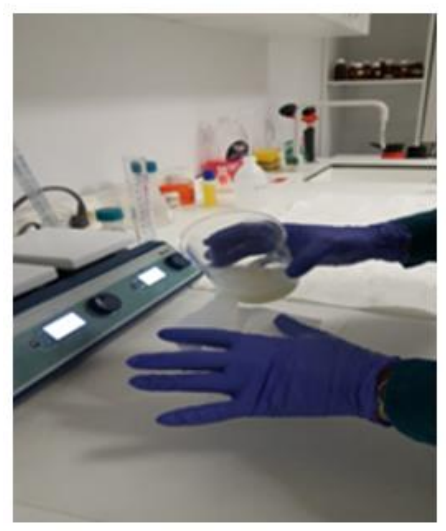

Günlük sakızı süzdürme

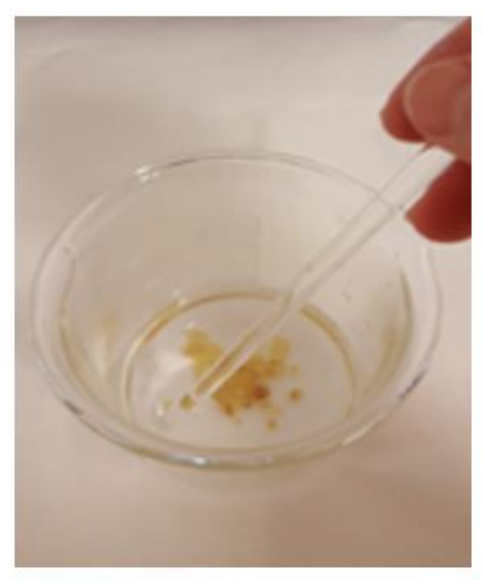

Günlük sakızı asetik asitte çözdürme

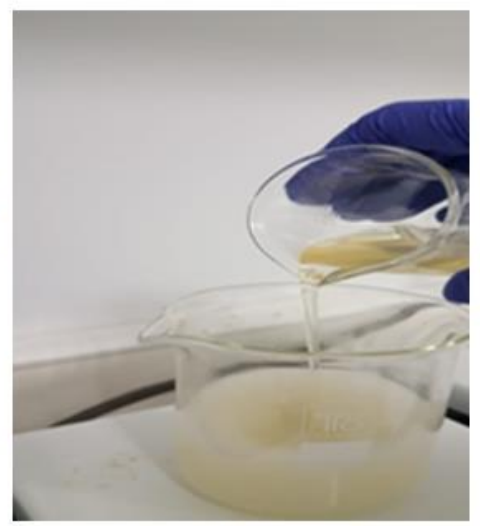

Aljinat ve günlük sakızı karıștırma

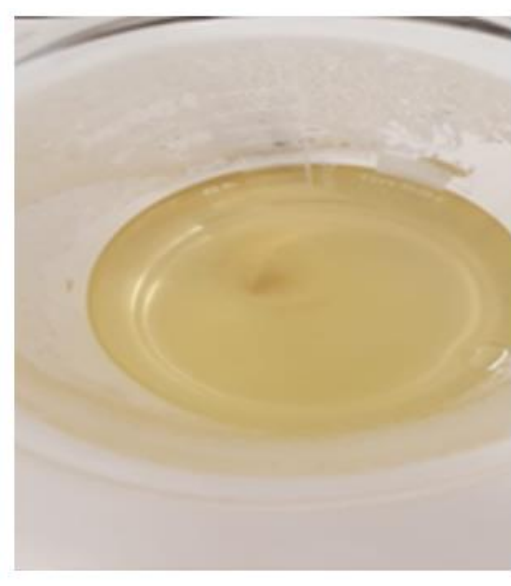

Aljinat çözeltisi

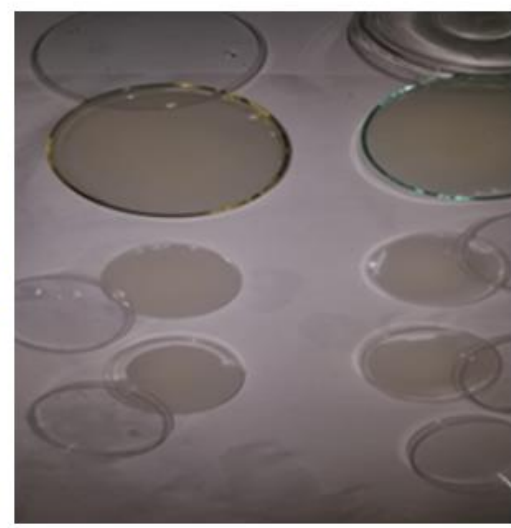

Aljinat ve günlük sakızı film olarak petri kaplarına döküldü

Şekil 7. Tuval temizliği için sakız ve aljinat hazırlama safhaları

\section{Bulgular}

\subsection{Optik mikroskop}

Yangınlar nedeniyle sanat eserleri üzerinde biriken is ve kül geri dönüşü mümkün olmayan sorunlara yol açmaktadır. Yüzeyde açık bir şekilde görülen is ve kül kirlendirme işlemleri sırasında tuvallerin yüzeyine uygulanmıştır. Toz, is ve külün yaşlandırma işlemi uygulanan tuval yüzeylerinde boyaların içerisine kadar ulaştığ görülmektedir. Tuval yüzeyinde küçük partikül yapısında tozlar izlenebilmektedir. Özellikle resimli tuvallerde kül ile kirlendirilmiş bölgeler incelendiğinde alt katmanlarda kırmızı renklerin yoğun olduğu yüzey üzerinde sarı bir görüntü oluşmaktadır. Boş tuval yüzeyine uygulanan yaşlandırma ve kirletme işlemleri 
neticesinde de özellikle beyaz astar tabakasında belirli bölgelerde yer yer kümelenmiş partikül yapıları görülmektedir. Şekil 8'de de görüldügü üzere astar tabakası yüzeyinde kül ile yapılan kirlenme işlemleri sarı renkli bir görüntü oluşturmuştur.

Kimyasal yöntemlerle yaşlandırma işlemi yapılan ve hidrojellerle temizlik işlemi uygulanan yüzeylerde işlemler iki grup malzeme üzerine uygulanmıştır. Yaşlandırma işlemi uygulanan ve is, kül, toz ile kirletilen tuvallere, hazırlanan hidrojel biyopolimerinin tuval yüzeyi üzerine iki dakika süreyle temizlik işlemi uygulanması ile gerçekleştirilen çalışmalarda temizlik işlemlerinin başarıyla yapıldığı ve çok iyi sonuçlar elde edildiği görülmektedir. Elde edilen biyopolimerik malzemelerin esnek bir yapıda olması nedeniyle tuval yüzeyindeki kıvrımlı ve çukur alanlara kadar ulaşılabildiği ve temizleme işlemlerinin bu alanlarda dahi başarıyla gerçekleştirildiği tespit edilmiştir. Kül, is ve toz ile kirletilen ve yaşlandırılan tuval yüzeylerine iki dakikalık hidrojel uygulamasında mükemmel bir sonuç elde edilmiştir. Şekil 8'de $\mathrm{H}_{2} \mathrm{O}_{2}$ ile yaşlandırılmış aynı zamanda aljinat-sakız hidrojeli ile temizlenmiş resimli ve boş tuval yüzeyleri görülmektedir.
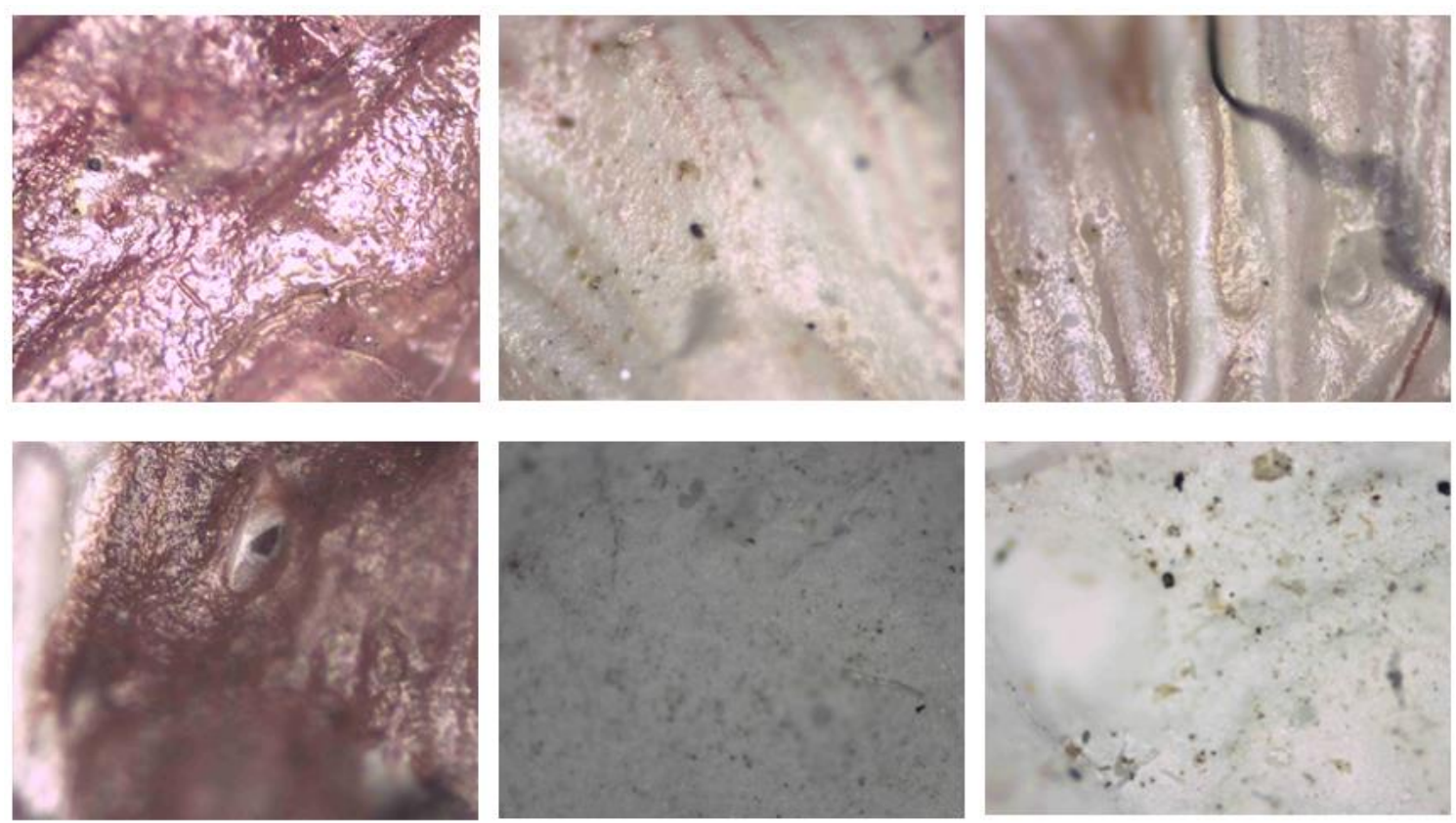

Şekil 8. $\mathrm{H}_{2} \mathrm{O}_{2}$ ile yaşlandırılmış aljinat+ sakız ile temizlenmiş tuval yüzeyleri

\subsection{Taramall elektron mikroskopu (SEM)}

Taramalı elektron mikroskopu; yapıyı çok detaylı görmemizi ve anlamamıza, görünenlerin çok iyi seviyede yorumlamamıza imkan sağlayan iyi bir karakterizasyon tekniğidir. [11]. Taramalı elektron mikroskopu; dört çeşit ana sistem üzerine kurulmuştur. Bunlar; enerji dağılımlı spektrometre (EDS), numune kutusu, optik kolon ve görüntüleme sistemlerinden oluşmaktadır. Bu teknikte, görüntü elde edebilmek için numunelerin yüzeyleri yüksek vakum ve voltaj altında taranır. SEM'de, çok yüksek enerji ve bir elektron demeti ile sert numunelerin yüzeyleri raster düzeninde taranır. Numunelerdeki demetin konumu, algılanan sinyallerle birleştirilerek görüntü oluşmasına imkan sağlarlar. Bu yöntem ve teknikte, yüzeyde çeşitli şekillerde sinyaller bir araya toplanır. Bu yöntem ve teknikte fazla yaygın olarak kullanılan; (SEM) taramalı elektron mikroskopunun ana temelini oluşturan, ikincil elektron ve $\mathrm{X}-{ }_{\text {ş̧ını }}$ emisyonunun geri saçılmasıdır. [12]. SEM ile boyalı yaşlandırılmış ve boş tuvaller ile farklı yaşlandırma ve kirletme işlem basamakları yapılan numunelerin yüzey görüntüleri 
incelenmiş ve boyaların yapılarıyla ilgili görüntülere erişilmiştir. SEM; partikül tanecikleri, büyüklükleri ve görüntüleri ile partikül morfolojisi ve dağılımındaki farklılıkları fiziksel ve kimyasal özellikleri hakkında bilgiye ulaşmamıza olanak vermiştir. Literatür verileri ile yaptığımız karşılaştırmada tuvallerin lif yapılarında oluşan bozunma ve kopmalar optik mikroskop sonuçlarına benzer ve aynı zamanda da veriler ile uyumludur $[2,9,13]$. Bilhassa inorganik pigmentlerin yapilarında mineralizasyon süreçleri incelenmiştir. $\mathrm{Bu}$ elde edilen bilgiler ayrıca konservasyon ve restorasyon çalışmaları için önem teşkil etmektedir. Aynı zamanda da analitik bilgilerin yorumlanmasında koruma ve onarımda doğru karar vermede yardımcı olabilecek düzeydedir. Şekil 9'da yaşlandırılmış yağlıboya tuval yüzeyi aljinat-sakız hidrojeli ile temizlenmiş tuvalin SEM görüntüsü verilmiştir.
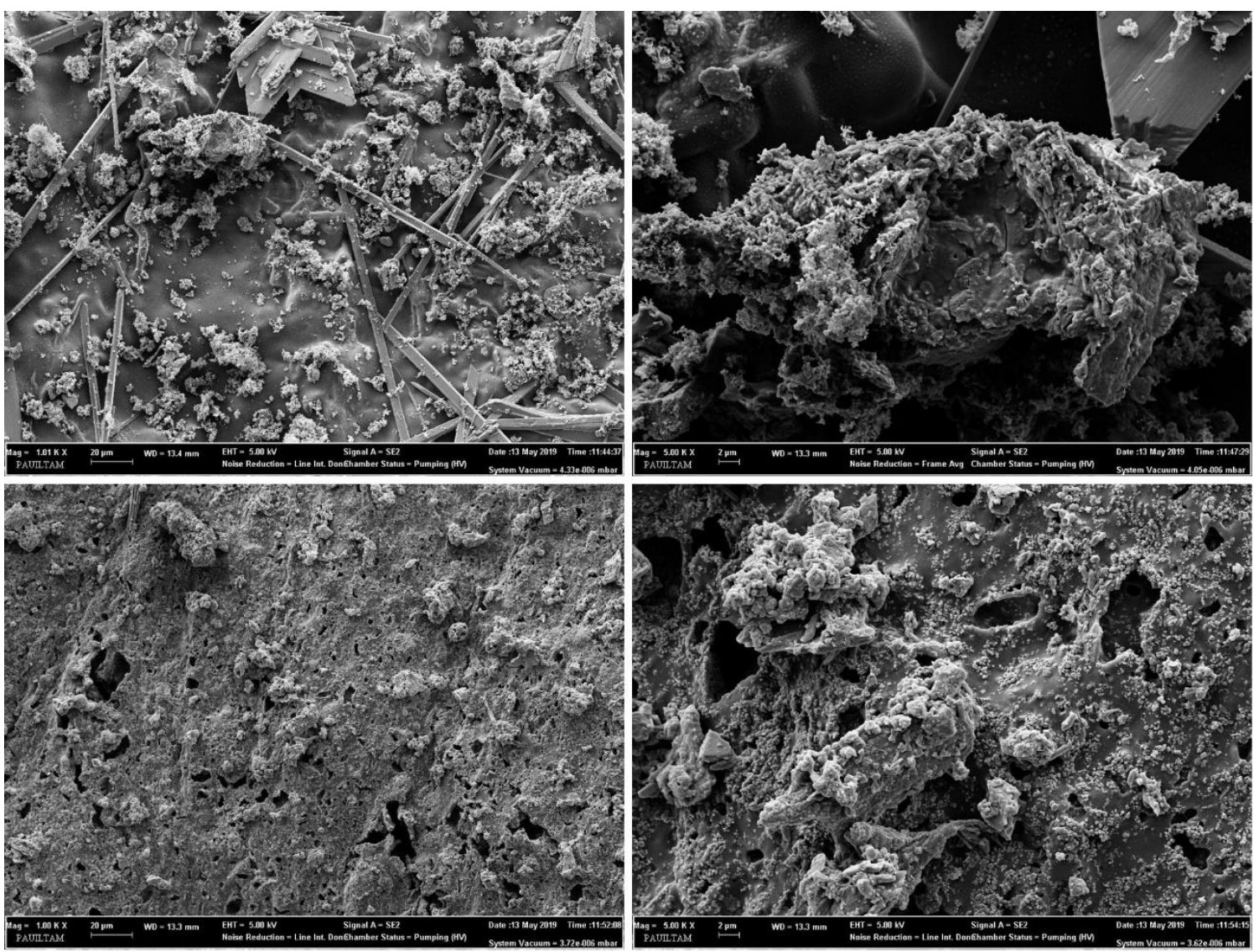

Şekil 9.Yaşlandırılmış yağlıboya tuval yüzeyi aljinat sakız ile temizlenmiş tuval SEM görüntüsü

\subsection{FTIR sonuçları}

K1zılötesi spektroskopisi (FTIR); organik veya inorganik bileşiklerin karakterizasyonunda tercih edilen analiz yöntem ve tekniklerinden bir tanesidir. Bu yöntem ve teknikte, maddeyi oluşturan atomlar arasındaki bağların titreşimi ile meydana gelen frekanslarına karşılık gelen piklerin soğurma işlemleri ile karakteri belirlenmektedir. FTIR, örneklere zarar vermeyen, aynı esnada da sonuçlara çok hızlı ulaşılmasına olanak sağlayan bir tekniktir [14]. FTIR spektrumlarından elde edilen verilere göre yağlı boya ve boş tuval yüzeyinde, çapraz bağlı polimer ağ yapıda hazırlanan hidrojel malzemelerin, yüzey temizleme işlem basamaklarından sonra çok fazla jel kohezyonu sebebiyle hidrojel kalıntıları görülmemektedir. Temizlenmiş tuval spektrumunda, biyopolimerik yapıda bulunan karbonil gerilme titreşimlerine ait karakteristik yoğun bantların (1724 ve $\left.1654 \mathrm{~cm}^{-1}\right)$ izlenememesi yağlı boya ve boş tuval 
yüzeylerinde saptanabilir hiçbir jel kalıntısı olmadığını doğrulamaktadır. Yapısında $\mathrm{Ca}^{+2}$ iyonları ile yumurta kabuğu modeline göre aljinat biyopolimerleri hidrojel oluşturan aljinatın $1500-1750 \mathrm{~cm}^{-1}$ çevresinde amid grubu $(\mathrm{C}=\mathrm{O}, \mathrm{C}-\mathrm{N}, \mathrm{N}-\mathrm{H}$ ve $\mathrm{C}-\mathrm{N}$ gerilme titreşimleri) piklerinden oluşmaktadır [9]. Şekil 10' da yaşlandırılmış kirletilmiş boş tuval ve resimli yaşlandırılmış kirletilmiş tuvallerin FTIR spektrumu izlenebilmektedir. Şekil 11 'de Hidrojen peroksit $\left(\mathrm{H}_{2} \mathrm{O}_{2}\right)$ ile yaşlandırılarak kirletilmiş ve aljinat sakız ile temizlenmiş tuvallerin FTIR spektrumu görülmektedir.

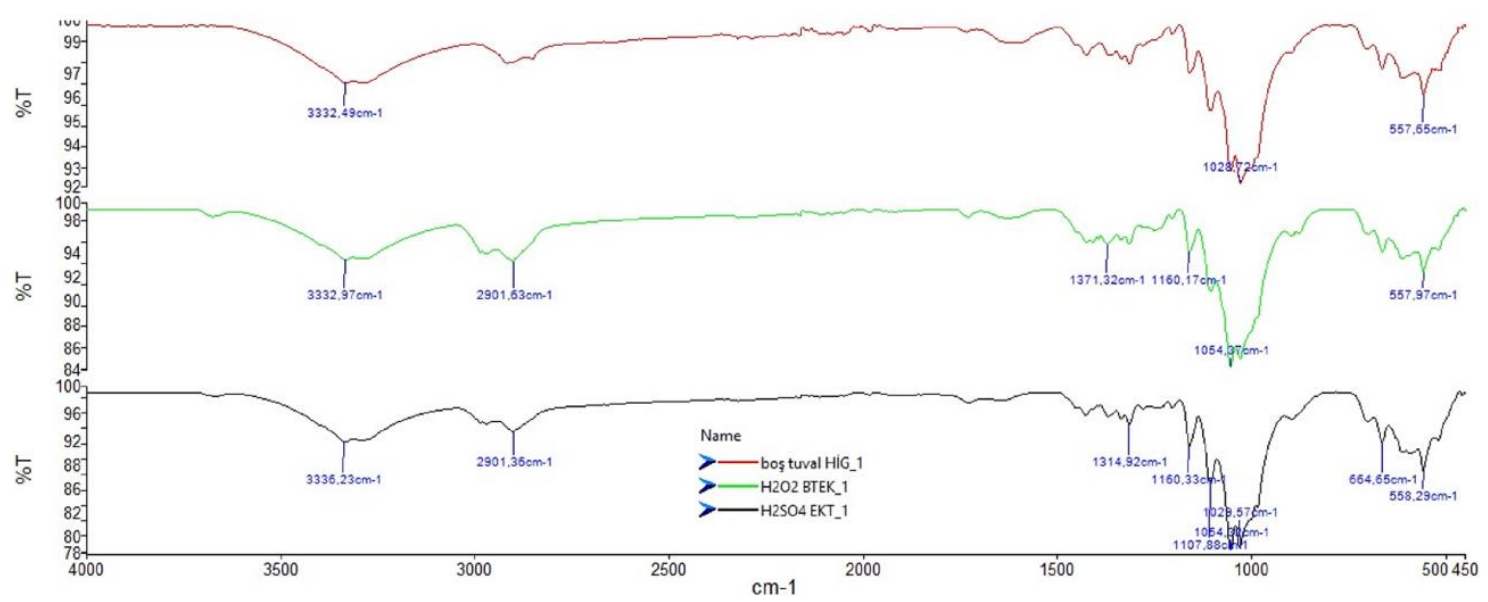

Şekil 10. Yaşlandırılmış kirletilmiş boş tuval ve yaşlandırılmış kirletilmiş resimli tuvallerin FTIR spektrumu

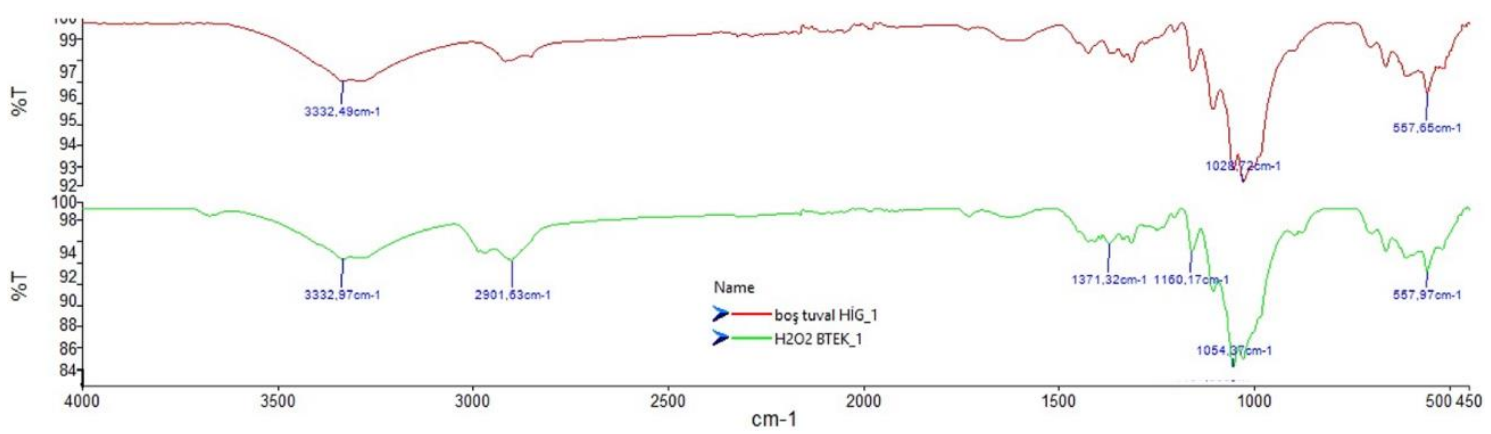

Şekil 11. $\left(\mathrm{H}_{2} \mathrm{O}_{2}\right)$ Hidrojen peroksit ile yaşlandırılarak kirletilmiş ve aljinat sakız ile temizlenmiş boş tuvallerin FTIR spektrumu

\section{Sonuç ve Yorum}

$\mathrm{Bu}$ çalışmada biyopolimerlerin özel bir türü olan hidrojeller kullanılarak yaşlandırma işlemi yapılarak bozunmaya uğramış ve yüzey kirliliğine maruz kalmış olan yağlı boya tuvallerin yüzeylerinin temizlenme işlemleri yapılmıştır. Yağlı boya tuvallerinin temizlik işlemlerinde birçok dezavantajı olmasına rağmen geleneksel yöntem ve teknikleri kullanılmaktadır. Gerek dünya gerek ülkemizdeki literatüre bakıldığında tuvallerin temizlenmesi konusunda yüzeye zarar vermeyen yenilikçi çalışmaların olduğu görülmektedir. \%85-90'dan fazla su bulunduran ve yumuşak bir malzeme olan hidrojeller, son zamanlarda biyomedikal alanlarında kullanımının yanı sıra ve aynı zamanda farklı sektörlerde de ilgi görmektedir. Hidrojeller kullanılarak tuval temizliği üzerine İtalya'da yapılmış olan bir çalışmaya rastlanmıştır. Hızlı ve ucuz işlemlerle doğal malzemelerden elde poly(2hydroxyethylmethacrylate)/polyvinylpyrrolidone hidrojeli yapılan çalışmada kullanıldığ1 görülmüsştür. 
Yağlı boya tuval yüzeyini temizlemek için aljinat gibi doğal biyopolimerik yapıda hidrojeller dünyada ilk defa rastlanılmıştır. Yaşlandırmaya tabi tutulmuş yağlı boya tuvallerinin kirletilmesinde özellikle toz, kül ve is kullanılmıștır. Sanat eserlerinde toz büyük bir sorun teşkil ettiğinden kirletme işleminin yapılmasında tozun kullanılması nedeni açıktır. Ayrıca kül ve isin tercih edilmesi sebebi ise tarihi önem sahip sanat eserlerinin yok olmasına neden olan yangınlardır. Yapmış olduğumuz çalışmanın neticesinde uygulama şekillerinde farklılıklarla ya da farklı şekillerde elde edilen biyopolimer malzemelerin, yüzeyde pigmentlerin oluşturduğu gözeneklerin içine nüfus eden is ve tozlara kadar ulaşıp en iyi şekilde temizlediği sonucuna varılmıştır. Dolayısıyla yaptığımız çalışmalar neticesinde, tarihi eser olma özelliği taşıyan yağlı boya tuval resimlerinde oluşan kirlenmelerin temizlenmesinde güçlü bir yöntem olarak biyopolimer malzemelerin kullanılmasının uygun olduğu izlenimine yol açmıştır. Çünkü çalışma sonucunda çıplak gözle görülebilecek kadar is ve toz temizliğinde mükemmel sonuçlar elde edilmiştir. Farklı şekillerde oluşturulan hidrojel filmler ile kirli alanlar optik mikroskopu altında temizlenebilir. Çalışmalarımızın neticesinde SEM analiz sonuçlarına göre hidrojellerin kullanıldığ 1 yüzeylerde temizlik sonrası pigmentlerin kristal yapılarında herhangi bir bozulmaya rastlanmamıştır. Ayrıca, temizlik işleminden sonra FTIR analizlerinde ise kullanılan hidrojellerin tuvallerin yüzeyinde hazırlanan filmlerde kalıntı bırakmadığı sonucu görülmüştür. Tüm çalışmaların sonucunda optik mikroskop, FTIR ve SEM analizlerine göre tuvallerin temizliğinde hidrojellerin kullanılabileceği anlaşılmıştır.

\section{Araştırmacıların Katkı Oranı Beyanı}

İbrahim KARATAŞ: Araştırma, Metodoloji Orijinal Taslak Yazımı.

Cem GÖK: Kaynak/Materyal/Malzeme Temini, Araştırma.

Dicle ERDEN GÖNENMIŞ: Kaynak/Materyal/Malzeme Temini, Denetim/Gözlem/Tavsiye.

Yusuf ÖZCAN: Denetim/Gözlem/Tavsiye, Doğrulama, İnceleme ve Düzenleme.

\section{Destek ve Teşekkür Beyanı}

$\mathrm{Bu}$ çalışmada bizlere araçların kullanımında katkıda bulunan, Pamukkale Üniversitesi, İleri Teknoloji Uygulama ve Araştırma Merkezi teknik personeline sonsuz teşekkür ederiz.

\section{Çatışma Beyanı}

$\mathrm{Bu}$ çalışmanın yazarları olarak herhangi bir çatışma beyanımız bulunmadığını beyan ederiz.

\section{Etik Kurul Onayı ve/veya Aydınlatılmış Onam Bilgileri}

$\mathrm{Bu}$ çalışmada görev alan araştırmacılar olarak herhangi bir etik kurul onayı ve/veya aydınlatılmış onam bilgilerine gerek olmadığını beyan ederiz.

\section{Kaynakça}

[1] G. Emre, "Yağlı boya tabloda koruma: Genel bir bakış," Restorasyon Konservasyon Çalışmaları Dergisi, 3, 74-77, 2009.

[2] S. Georgiou, V. Zafiropulos, D. Anglos, C. Balas, V. Tornari and C. Fotakis, "Excimer laser restoration of painted artworks: procedures, mechanisms and effects," Appl. Surf. Sci., 127-129, 738745, 1998.

[3] G. Yaşayan, "Yağlı Boya Tablo Koruma ve Onarımında Yüzey Temizliğinin Etkilerinin Araştırılması," Yüksek Lisans Tezi, Taşınabilir Kültür Varlıklarını Koruma ve Onarım A. D., İstanbul Üniv., İstanbul, Türkiye, 2014.

[4] J. Harr, "Kayıp Tablo, (Çev. Taner Gezer, İsa Bayrak)," Yakamoz yayınları, İstanbul, 2010, pp. 178179. 
[5] F. Nockher, Suluboya Resim ve Suluboya ile Resim Yapma Tekniği, (Çev. H. Gölkıyı), İstanbul: MEB Yayınevi, 1961, pp. 1961.

[6] K. Nicolaus, The Restoration of Paintings, Slovenia: Könemann, 1999, pp. 312, 335.

[7] B.Y. Büyükakıncı, "Hava Kirliliğinin Tarihi Eserlere Etkisi ve Alınması Gereken Önlemler," T.C. Anadolu Bil Meslek Yüksek Okulu Dergisi, 19, 47-52, 2010.

[8] J. M. Parramón, Yağlıboya Resim Sanatı, (Çev. Erol Erduran), Remzi Kitabevi: İstanbul, 2012, pp. 35-36.

[9] O. Nechyporchuk, K. Kolman, M. Oriola, M. Persson, K. Holmberg, and R. Bordes, “Accelerated ageing of cotton canvas as amodel for further consolidation," J. Cult. Herit., 28, 183-187, 2017.

[10] C. Gök, "Uranyum ve Toryumun Adsorpsiyonu için Aljinat Biyopolimerlerinin Hazırlanması ve Çeşitli Uygulama Alanlarının İncelenmesi,” Doktora Tezi, Fen Bilimleri Enstitüsü, Ege Üniv., İzmir, Türkiye, 2010.

[11] S. Amelinckx, D. Van Dyck, J. Van Landuyt and G. Van Tendeloo, Electron Microscopy Principles and Fundamentals, Antwerp: A Wiley Company, 1997, pp. 306.

[12] M. Ohring, The Materials Science of Thin Films, Academic Press: New Jersey, 1992, pp. 266-268.

[13] J. A. L. Domingues, N. Bonelli, R. Giorgi, E. Fratini, F. Gorel, P. Baglioni, Innovative hydrogels based on semi-interpenetrating $\mathrm{p}(\mathrm{HEMA}) / \mathrm{PVP}$ networks for the cleaning of water-sensitive cultural heritage artifacts, Langmuir, 29(8), 2746-2755, 2013.

[14] T. Büyüksırıt, H. Kuleaşan, "Fourier Dönüşümlü Kızılötesi (FTR) Spektroskopisi ve Gıda Analizlerinde Kullanımı," Glda, 39 (4), 235-241, 2014. 